\title{
Bread and Other Edible Agents of Mental Disease
}

\author{
Paola Bressan * and Peter Kramer \\ Department of General Psychology, University of Padua, Padova, Italy
}

Perhaps because gastroenterology, immunology, toxicology, and the nutrition and agricultural sciences are outside of their competence and responsibility, psychologists and psychiatrists typically fail to appreciate the impact that food can have on their patients' condition. Here we attempt to help correct this situation by reviewing, in non-technical, plain English, how cereal grains - the world's most abundant food source-can affect human behavior and mental health. We present the implications for the psychological sciences of the findings that, in all of us, bread (1) makes the gut more permeable and can thus encourage the migration of food particles to sites where they are not expected, prompting the immune system to attack both these particles and brain-relevant substances that resemble them, and (2) releases opioid-like compounds, capable of causing mental derangement if they make it to the brain. A grain-free diet, although difficult to maintain (especially for those that need it the most), could improve the mental health of many and be a complete cure for others.

Keywords: exorphins, food opioids, celiac disease, gluten sensitivity, gluten-free diet, microbiota, schizophrenia, autism

OPEN ACCESS

Edited by:

Rajeev Krishnadas,

NHS Greater Glasgow and Clyde/University of Glasgow, UK

Reviewed by:

Paul Whiteley, ESPA Research, UK Jessica Rose Biesiekierski,

KU Leuven, Belgium

*Correspondence:

Paola Bressan paola.bressan@unipd.it

Received: 06 January 2016 Accepted: 10 March 2016 Published: 29 March 2016

Citation: Bressan P and Kramer P (2016) Bread and Other Edible Agents of Mental Disease.

Front. Hum. Neurosci. 10:130. doi: 10.3389/fnhum.2016.00130

\section{INTRODUCTION}

"Give us this day our daily bread (. . ) but deliver us from evil" -Matthew 6:11, 13

About 12,000 years ago, when the last ice age came to an end, the rapid change in climate decimated our traditional food sources, especially large game. Possibly in response to that, in the fertile crescent of the Middle East (roughly the areas comprising the Levant and the Tigris and Euphrates valleys) we began to practice agriculture and animal domestication. Within a few thousand years both had independently started on at least four different continents (Murphy, 2007), stabilizing and increasing our food supply to such an extent that the human population exploded. Yet the agricultural revolution not only increased the availability of food, but also radically changed its nature: cereal grain products, to which we were largely unaccustomed, quickly took center stage. This article illustrates the surprising relevance of this diet change to neuroscientists, psychologists, and psychiatrists.

That the association between humans and grains paid off nicely for both is beyond dispute. Each partner helped the other reproduce, multiply, and ultimately conquer vast patches of the earth. Each partner coevolved with the other, adapting to it. For example, wheat progressively became shorter in response to our own preference for crops easier to harvest and less vulnerable to wind. At the same time, our faces, jaws, and teeth progressively 
became smaller in response to the soft texture of bread (Larsen, 1995). Thus we domesticated grain, and in return grain domesticated us (Murphy, 2007).

Yet the agricultural revolution may have spelled trouble. Tellingly, whenever diets based on grain replaced the traditional diets of hunter-gatherers, lifespan and stature decreased-while infant mortality, infectious diseases, bone mineral disorders, and the frequency of dental caries increased (Cohen, 1987). Some of these problems were never totally overcome. For example, despite a gradual increase in stature beginning 4,000 years ago, when diets became more varied again, on average we are still about $3 \mathrm{~cm}$ shorter than our pre-agriculture ancestors (Murphy, 2007). The coevolution between humans and grain brought on genetic changes in both parties, but did not render grain a more suitable food for us than it originally was.

One of the first hints that these circumstances could have implications for the psychological sciences was the observation that, in several countries, hospitalization rates for schizophrenia during World War II dropped in direct proportion to wheat shortages. In the United States, where over that same period the consumption of wheat rose rather than diminished, such rates increased instead (Dohan, 1966a,b). In South Pacific islands with a traditionally low consumption of wheat, schizophrenia rose dramatically (roughly, from 1 out of 30,000 to 1 out of 100) when Western grain products were introduced (Dohan et al., 1984).

There is now substantial evidence that, depending on genes carried by over one third of us and on seemingly irrelevant factors such as a previous viral infection, eating bread can adversely affect our body and brain. This article reviews the evidence for a wide readership in non-technical, plain English. The next three sections present the implications for the psychological sciences of the facts that bread (1) increases the permeability of the gut and likely of the blood-brain barrier in all of us, (2) sets off an immune reaction in those of us who are genetically predisposed, and (3) breaks down, during digestion, in fragments with opioid activity. The final section discusses whether a change in diet could possibly cure patients with mental illness.

\section{GRASSES, GRAINS, AND POISONS}

Grains are the seeds of grasses. Grasses may or may not have evolved to let their seeds be eaten (Janzen, 1984), but certainly not to let them be digested into pieces that will be incapable of passing on the plant's genes. Grasses cannot defend themselves by fleeing or fighting, they have no thorns, they carry no protective hard shell around their seeds; like most plants, however, they produce toxins. Plants have engineered a wide variety of poisons-over 50,000 defensive compounds have been identified so far (Kennedy and Wightman, 2011) - to deter, harm, or kill the creatures that feed on them. These creatures, in turn, have evolved an arsenal of countermeasures, including mechanisms to detect (for example, bitter taste receptors) and detoxify such poisons as much as possible (Hagen et al., 2009).

Understandably, self-defense proteins are especially concentrated in plants' most precious fraction-the seeds.
Ironically, of the three separate genomes that modern wheat contains from the spontaneous cross-fertilization of three different wild species (e.g., Murphy, 2007), the genome responsible for the best quality bread is associated with the most toxic proteins (Kucek et al., 2015). These are capable, at least in rodents, of crossing both the gut and the blood-brain barriers (Broadwell et al., 1988) and interfere, among other things (Pusztai et al., 1993), with the action of nerve growth factor (Hashimoto and Hagino, 1989). In pasta, many of these proteins-though highly resistant to digestion-are lost in the salted water during cooking, hence they do not make it to the final dish (Mamone et al., 2015). Yet they can still be found in beer and pre-steamed couscous (Flodrová et al., 2015) and can be inhaled from raw flour (Walusiak et al., 2004).

Seeds are also equipped with proteins designed to provide ready-made nourishment for the future seedling. The kit of storage proteins in barley, rye, and particularly wheat, known as gluten ("glue" in Latin), has turned out to have special value for us. As bread dough is kneaded, gluten forms an elastic network that traps the gases produced by yeast during fermentation; this allows the dough to rise and to expand during baking. The spectacular success of wheat relative to barley and rye has mainly hinged on the ease with which a light, porous, optimally chewy bread can be obtained from its flour.

Unfortunately, gluten has proven to be toxic for a proportion of people that in the last few decades has been constantly rising (Rubio-Tapia et al., 2009). Indeed, the wheat varieties that contain the most detrimental type of gluten have become more common (van den Broeck et al., 2010). This is particularly worrying given that gluten is not only naturally present in bread, cake, pasta, pizza, and beer, but it is-for its binding and thickening properties-also added to an impressive variety of other products. A survey of Australian supermarkets found gluten in nearly 2,000 different food items, ranging from sauces to processed meats, and over 100 non-foods, from pain relievers to shampoos (Atchison et al., 2010). Yet gluten triggers some action as soon as it turns up in the gut-not only in a few sensitive people, but in all of us.

\section{HOLES IN OUR GUT}

A post-mortem study of 82 schizophrenia patients found rates of stomach, small intestine, and large intestine inflammation as impressive as respectively $50 \%, 88 \%$, and $92 \%$ (Buscaino, 1953; cited in Buscaino, 1978). The association between gastrointestinal pathologies and psychiatric disorders had already been noticed at least 2,000 years ago and has been confirmed repeatedly (for a brief review see Severance et al., 2015).

An unhealthy gut may open up our body to harmful bacteria, toxins, and undigested pieces of food. In each of us, an intestinal wall whose surface could pave an entire studio apartment (Helander and Fändriks, 2014) faces the challenge of preventing this from happening, while letting water and nutrients through. This feat is accomplished via a sophisticated barrier, where the 
opening and closing of the junctions between the wall's cells are adjusted flexibly (Bischoff et al., 2014). Other than that, this architecture might serve as an emergency line of defense against pathogenic microbes (Fasano et al., 1997). The part of the gut that immediately follows the stomach, the small intestine, is in fact kept virtually sterile-bacteria are removed by the peristaltic movements of the gut before they can multiply (Dixon, 1960). Any abnormal presence of microbes triggers the release of the protein zonulin, which widens the junctions between cells so that water can seep into the intestine and flush out bacteria via loose bowel movements (El Asmar et al., 2002).

Producing diarrhea is just one exceptional job among the many, less conspicuous daily ones that zonulin is believed to perform. Importantly, regulation of intestinal permeability grants or vetoes the passage of large molecules and immune cells. For still obscure reasons, however, sometimes this mechanism allows partially undigested food components to escape from the gut and reach (a) the inner layer of the intestinal wall, which hosts a large part of the immune system, and (b) the bloodstream. These substances are not expected there and can set in motion a misdirected immune reaction (for a readable account of the details, see Fasano, 2009). Protracted abnormal gut permeability is indeed associated with a wide range of immunerelated diseases, and in some animal studies has been shown to precede them, suggesting causation (e.g., Meddings et al., 1999). These diseases include arthritis, asthma, type 1 diabetes, and multiple sclerosis (Fasano, 2012).

It is worth noting that psychological stress worsens gut permeability. Speaking in public does it, with transient effects (Vanuytsel et al., 2014), and early maternal deprivation does it too, with long-term ones (demonstrated in rats: Barreau et al., 2004). Interestingly, psychological stress also worsens gut inflammation (for a brief review, see Daulatzai, 2015), exacerbates immune-related diseases (Dhabhar, 2009), and predicts the onset and severity of mental disorders (Kendler et al., 1999; Carr et al., 2013). Some common spices (JensenJarolim et al., 1998) and food components (e.g., Bischoff et al., 2014) modulate gut permeability too, either increasing it (like fructose, widely used to sweeten commercial beverages) or decreasing it (like the flavonoid quercetin, found in onions and tea). Probably because it is mistaken for a microbial molecule (Fasano et al., 2015), gluten stimulates zonulin release and hence features prominently in the former group (Hollon et al., 2015). Ingestion of an inhibitor of zonulin prevents gluten from raising gut permeability, and a gluten-free diet reduces both zonulin levels and gut permeability (Fasano, 2011). In all of us, zonulin increases the permeability not only of the intestinal wall, but also of other no less interesting barriers-notably the bloodbrain one. A toxin mimicking zonulin is actually being studied for its ability to enhance delivery to the brain of drugs such as anticancer agents (Karyekar et al., 2003).

\section{IMMUNE SYSTEM MISTAKES}

After increasing gut permeability and with its help, gluten can make trouble if it happens to cross the outer layer of the intestinal wall and become the target of immune surveillance. The next two subsections explore the consequences of this encounter on our body and on our brain.

\section{The Many Forms of Wheat Sensitivity}

Some people are overtly allergic to wheat (from here on, "wheat" will cover all gluten-containing grains). Minutes to hours after exposure, these individuals develop symptoms such as rashes, headaches, diarrhea, or shortness of breath-a well-known example is baker's asthma. This wheat allergy (Inomata, 2009) engages the part of our immune system that responds quickly against parasitic worms, fungi, and microorganisms. In some of us, however, gluten triggers immune-mediated reactions whose symptoms develop gradually, weeks to years after its introduction in the diet.

In about 1 person out of 100 this hypersensitivity is expressed as celiac disease, defined as a chronic immune reaction against one's own small intestine. Over time, this reaction flattens the intestinal wall (which is normally covered with millions of finger-like protrusions), reducing its surface and thus its ability to absorb important nutrients for both body and brain. If gluten is not withdrawn during childhood, the growth of some cranial bones is altered as well. As a result, over $80 \%$ of adult celiacs have unusual facial proportions (Zanchi et al., 2013). Quite typical is an especially high forehead relative either to the middle third of the face or to the forehead of healthy people (see, respectively, Finizio et al., 2005; and Zanchi et al., 2013).

Most people with celiac disease do not know they have it. In a sample of over 5,000 Italian students, for example, the ratio of diagnosed to undiagnosed cases was 1 to 6 (Catassi et al., 1995). In the elderly, celiac disease often goes unrecognized as well, with a mean delay of 17 years from the onset of symptoms to diagnosis (Gasbarrini et al., 2001). Alarmingly, blood markers of the disease have quadrupled in the United States in the last 50 years (Rubio-Tapia et al., 2009) and doubled in Finland in the last 20 (Lohi et al., 2007). Measurements were taken all at once on blood samples collected and frozen decades apart, hence the recent surge in the disease cannot be due to better detection or more lenient diagnostic criteria. Markers also increase within the same group of individuals over time, showing that an abnormal immune response to gluten can suddenly emerge in adulthood (Catassi et al., 2010).

Some people do better on a gluten-free diet and worsen upon a gluten challenge (even under double-blind, randomized, placebo-controlled conditions: Biesiekierski et al., 2011) although they do not meet the criteria of either wheat allergy or celiac disease. This non-celiac gluten sensitivity is diagnosed by exclusion, because there are currently no laboratory tests for it. The gut permeability of these people is normal, unlike that of celiacs-but gluten makes it soar just as much as that of celiacs (Hollon et al., 2015). Symptoms emerge hours to days after gluten exposure and are largely extraintestinal; they include headache and eczema but also fatigue and "foggy mind" (Sapone et al., 2012). Other individuals report being sensitive to gluten but actually experience bloating and abdominal pain from wheat's carbohydrates (Biesiekierski et al., 2013). Many 
studies on non-celiac gluten sensitivity have not controlled for the presence of these carbohydrates; they can also be found in various vegetables, however, and whether their effects can go beyond mere intestinal discomfort is debatable (for opposing views, see Fasano et al., 2015; De Giorgio et al., 2016).

Over $95 \%$ of celiacs carry a specific variant of a gene that is corresponsible for the regulation of the immune system, and about 5\% carry another (Diosdado et al., 2005). Crucially, both genes are implicated in the ability of the immune system to distinguish self from non-self. These genes are also present in $30-40 \%$ of the general population, however, and of course not all of them develop celiac disease; even monozygotic twins on the same diet can be discordant for it (Greco et al., 2002). Other factors must thus be involved-possibly, simple environmental triggers. These have been shown to range from delivering a baby (Malnick et al., 1998) to contracting a virus or a parasite. In one study, for example, nearly $90 \%$ of celiacs, vs. $17 \%$ of controls, showed evidence of previous infection with adenovirus (Kagnoff et al., 1987). Because a protein coded by this virus is structurally similar to gluten, it is plausible that in genetically predisposed individuals the initial reaction to the virus may extend to gluten and then to some proteins in our own intestine that resemble both - a process called molecular mimicry (see Kasarda, 1997).

\section{Wheat and the Mind}

Unfortunately, gluten resembles some brain-relevant substances too. In vitro, antibodies against gluten removed from human blood attack cerebellar proteins and components of the myelin sheath that insulates nerves (Vojdani et al., 2014). They also attack an enzyme involved in the production of GABA-our prime inhibitory neurotransmitter, whose dysregulation is implicated in both anxiety and depression. In the blood of blood donors, antibodies against wheat or milk and antibodies against these brain-relevant substances have been found to be simultaneously elevated, consistent with the presence of a cross-reaction (Vojdani et al., 2014). Most of us escape it only because our gut and blood-brain barriers are intact-and only as long as they remain so. Antibodies against the brain, triggered by gluten, can cause severe neurological dysfunctions whether or not one is celiac (Hadjivassiliou et al., 2010). Similar antibodies have also been found in the blood of a subgroup of schizophrenia patients; some of them carried blood markers of celiac disease, but others did not (Cascella et al., 2013).

If wheat can affect the brain, it should come as no surprise that it can affect mental health too (for a review, see Jackson et al., 2012a). Exceptionally large epidemiological studies, each involving many thousands of patients, have found that celiac disease is associated with an increased risk of depression (Ludvigsson et al., 2007b) and psychosis (Ludvigsson et al., 2007a). Among individuals with a normal intestinal wall, those who carry blood markers of celiac disease are three times more likely to develop autism in the future, and five times more likely to have already been diagnosed with it (Ludvigsson et al., 2013).
Antibodies against gluten have been found much more often in schizophrenia and autism patients than in the general population or in controls, a result that has been replicated repeatedly (Jackson et al., 2012a). Some figures are stunning, such as a reported presence of antibodies against gluten in $87 \%$ of unmedicated autistic children vs. $1 \%$ of normal children (Cade et al., 2000).

\section{Microbial Accomplices}

The main gene that predisposes to celiac disease also changes the composition of the microbes in the gut; a notable finding, because we now know that these microbes (collectively known as gut microbiota) are directly capable of shaping our behavior (Dinan et al., 2015; Kramer and Bressan, 2015). Carriers and non-carriers of the gene produce stools with significant bacterial differences at 1 month of age already (Olivares et al., 2015). Among other things, carriers host more clostridia; clostridia tend to be overrepresented in the guts of children with autism (Louis, 2012), and it is suggestive to associate these findings to the epidemiological evidence, discussed earlier, of a larger risk of autism in celiacs.

Gut microbes even appear to play a part in when (and possibly whether!) carriers do develop celiac disease. Because the maturation of our immune system is co-driven by our microbial community (Kranich et al., 2011), it is crucial that the latter develops normally-which could be jeopardized by feeding babies inappropriate foods at an inappropriate time. The microbiota matures enormously in the first 12 months of life, hence it might be important to avoid gluten during this period (Fasano, 2009). Indeed, a double-blind study on young carriers of the celiac gene compared the relevance of early (6 months of age) vs. late (12 months) introduction of gluten in their diets. Early introduction promptly caused loss of tolerance to gluten and set off the development of autoimmunity, arguably via a change in the composition of the still immature microbiota (Sellitto et al., 2012). Indeed, whether or not transgenic mice with the celiac gene in them express the disease has recently been shown to be entirely determined by their guts. Eating gluten started celiac disease in the mice who had been raised without gut microbes, or whose microbiota included pathogens or had been perturbed by antibiotics right after birth-but not in the mice whose microbiota was healthy (Galipeau et al., 2015).

Changes in gut microbiota due to a sudden, massive exposure to wheat products have also been hypothesized to mediate the well-known relationship between immigrant status and schizophrenia (Severance et al., 2014). This might be, for example, the case of people moving to Europe from subSaharan Africa, where staple grains do not include wheat and are traditionally broken down via fermentation before being eaten. It is thus entirely possible that bread can be harmful to our mental health not only directly, via some of the proteins it contains; but also indirectly, via its effects on our gut microbes. The causal relationship between eating bread and harboring certain microbes could actually go both ways, as suggested by recent evidence that our craving for certain foods may be driven by the 
intestinal bacteria that feed on them. Bread is ultimately broken down to sugar, and plenty of microbes thrive on sugar. When not enough of it comes their way, microbes might be able to manipulate their host by inducing bad mood and other painful sensations - relieved only by eating the right stuff (Alcock et al., 2014).

\section{BREAD AND OTHER DRUGS}

During digestion, gluten is broken down into hundreds to thousands of fragments that are not further dissolved. Some of them resemble morphine extremely much and have thus been named exorphins (where "exo" refers to their external origin; Zioudrou et al., 1979). Exorphins are released from other proteins as well-prominently casein, found in milk and very similar to gluten, but also albumin in rice and zein in corn (Teschemacher, 2003). How exorphins affect our behavior, and what happens if they are absorbed from the gut and show up in the brain, are the topics of the next two subsections.

\section{Exorphins Posing as Endorphins}

Like morphine, exorphins bind to opioid receptors that are widely distributed throughout the body-in places as different as the gut, the lungs, the genitals, the various districts of the nervous system. Such receptors are of course meant for our own opioids, endorphins (of internal origin, "endo"). Our body may produce endorphins to reduce pain when we need to continue functioning in spite of injury or stress, as during labor or combat. The "runner's high", the state of euphoria experienced by long-distance runners, might capitalize on this mechanism (Boecker et al., 2008; but see also Fuss et al., 2015).

It has been intriguingly suggested that one major function of endorphins would be to protect the organism against starvation in times of stressful, prolonged food scarcity (Margules, 1979, 1988). We know that the same opioid can exert opposite effects depending on which receptor it binds to (Teschemacher, 2003); the key might be whether the receptor happens to sit in the body or in the brain (Margules, 1988). Bound to opioid receptors in the gut, in fact, morphine-like endorphins tend to conserve bodily resources (by inducing constipation and water retention), reduce motor activity, decrease pain, suppress both reproduction hormones and sexual desire. Bound to opioid receptors in the brain, on the contrary, they promote energy expenditure, boosting reactivity and (hyper)activity. The former could be interpreted as a passive, hibernation-like response to seasonal food shortage; the latter as an active, migration-inducing one (Margules, 1988; see also Guisinger, 2003). The potential connection between a malfunctioning opioid system and eating disorders such as anorexia has not gone unnoticed-and it is supported by several lines of evidence (see Yeomans and Gray, 2002). Notably, endorphins are produced on demand, but exorphins are generated at virtually every (modern) meal.

Food exorphins appear to perform their job largely or entirely from the gut. Thus, they should support energy sparing in all kinds of manners (see evidence for some of these in
Teschemacher, 2003). Yet exorphins directly bind to the opioid receptors of the brain as well, if they can get there (Kostyra et al., 2004). The question is whether they pass through the intestinal and blood-brain barriers in meaningful amounts. Some authors argue that, if these barriers are healthy, they probably do not (Miner-Williams et al., 2014). This is hardly reassuring, though, given how easily the function of even healthy barriers can be disrupted-be it by stress (Söderholm and Perdue, 2001), dietary components (Ulluwishewa et al., 2011), alcohol (Purohit et al., 2008), or familiar over-the-counter drugs (e.g., Smale and Bjarnason, 2003). Indeed, radioactively labeled gluten proteins fed to rats by stomach tube are later found in the animals' brains in the form of exorphins (Hemmings, 1978; for related evidence regarding dairy proteins, see Sun and Cade, 1999).

The manufacture of exorphins is incredibly efficient. The nutritionally insignificant intake of $1 \mathrm{~g}$ of casein (about two tablespoons of cow milk), for example, produces opioids in large enough amounts to exert physiological effects (Meisel and FitzGerald, 2000). This is remarkable in view of the facts that (a) the opioids from gluten are stronger than those from casein (Zioudrou et al., 1979), and (b) the daily average consumption of gluten in Europe is 10-20 g, with many people exceeding $50 \mathrm{~g}$ (Sapone et al., 2012). In the brain of rats, the opioids from casein have been shown to be 10 times more potent than morphine (Herrera-Marschitz et al., 1989). If all exorphins released in the gut made it to the brain, it is hard to see how we could keep functioning.

Opioids are involved in both the palatability and rewarding aspects of food, hence they play a major role in food cravings and food addiction (for a review, see Yeomans and Gray, 2002). The opioid antagonist naloxone drastically reduces the intake of preferred foods, but not of nonpreferred ones, in rats (Glass et al., 1996; see also Boggiano et al., 2005). Naltrexone, which is much like naloxone but it lasts longer and can be taken by mouth, suppresses binge eating in humans (Marrazzi et al., 1995). Indeed, people who have first ingested naltrexone (against placebo: Yeomans and Gray, 1997) rate a bowl of pasta as less pleasant, and eat less of it. Tellingly, naloxone is famed for its ability to counteract the effects of an overdose of heroin, a potent derivative of morphine, and naltrexone is used in the treatment of heroin dependence.

Foods that contain exorphins, such as wheat and dairy products, have indeed a reputation for being rewarding and people find it extremely hard to give them up. The addictive properties of milk were arguably designed by evolution to gratify suckling young. The gut of newborns is highly permeable-not only to the mother's antibodies as an aid to their still immature immune system, but also to milk opioids (see Teschemacher, 2003). Yet, production of the enzyme for properly digesting milk is genetically programmed to stop after weaning. Regular intake of milk by adults is evolutionarily novel and only started with animal domestication; it was permitted by a mutation of this enzyme in populations that kept cattle. Interestingly and perhaps worryingly, the opioids in bovine milk are 10 times stronger than those in human milk (Herrera-Marschitz et al., 1989). This might not be extraneous to the fact that about half of children up to 
4 years of age need their milk bottle to fall asleep at night (in Thailand: Sawasdivorn et al., 2008). Note that, as mentioned, the opioids in wheat are even stronger than those in bovine milk (Zioudrou et al., 1979).

Arguably, foodstuffs whose digestion releases exorphins are preferred exactly because of their drug-like properties. It has been speculated, in fact, that this chemical reward might have been one incentive for the initial adoption of agriculture (Wadley and Martin, 1993). Why cereals rapidly and extensively replaced traditional foods even though they were less nutritious and required more labor has been widely regarded as a puzzle. Also, cultivation of cereals continued even when the abundance of more easily processed foodstuffs-such as meat, tubers, and fruit-rendered it unnecessary (see Murphy, 2007). A clue could be the fact that all major civilizations, in every inhabited continent, arose in groups that practiced cereal agriculture and not in groups that only cultivated tubers and vegetables or had no agriculture at all. According to Wadley and Martin's rather audacious hypothesis, daily opioid self-administration could have increased people's tolerance of crowded sedentary conditions, of regular work, of subjugation by rulers. If so, cereals might have ultimately helped the development of civilization.

\section{Too Much Exorphin in the Wrong Place}

Not all individuals handle these substances the same way. For example, abnormally high levels of milk and/or wheat exorphins have been found in the urine (Hole et al., 1979) and blood (Drysdale et al., 1982) of schizophrenia patients and in the urine (e.g., Sokolov et al., 2014; but see Cass et al., 2008) of autistic children. When purified and injected in the brain of rats, these substances made the rats behave in strikingly odd ways-very restless at first and then inactive and hyperdefensive. Among other things, the rats paid no attention to a ringing bell, in suggestive similarity to the apparent deafness often observed in children with autism (Sun and Cade, 1999; Cade et al., 2000). Interestingly for the nonpatients among us, exorphins coming from healthy people's blood had on rats effects that were weaker and briefer but otherwise similar (Drysdale et al., 1982).

Besides producing behavioral disorders similar to those seen in schizophrenia and autism (such as decreased social interaction, reduced pain sensitivity, uncontrolled motor activity: Sun and Cade, 1999), exorphins activate in rats the same brain regions that are affected in schizophrenia and autism. The disruptive effects they exert on visual and auditory areas are consistent with typical malfunctionings such as hallucinations in schizophrenia (Sun et al., 1999). So perhaps it is no coincidence that a recent case report of an adult patient has described complete resolution of highly unsettling visual and auditory hallucinations, experienced daily from early childhood, upon removal of gluten from the diet (Genuis and Lobo, 2014).

The effects of food exorphins on behavior (for a comprehensive review, see Lister et al., 2015) and on the brain (Sun et al., 1999) are reversed by treating the rats with opioid antagonists. Naloxone has also been shown to temporarily erase psychotic symptoms, especially hallucinations, in schizophrenia patients (Emrich et al., 1977; Jørgensen and Cappelen, 1982). Naltrexone benefits some children with autism (Roy et al., 2015), arguably by blocking a brain opioid activity that might be abnormally high in these children (Sahley and Panksepp, 1987). Attempts to eliminate excess exorphins from the blood of schizophrenia patients via weekly dialysis for 1 year have led to remarkable results as well, with $40 \%$ of patients vastly improving or fully recovering from schizophrenia. In some patients who did not get better, the continuous production and absorption of exorphins on a regular diet might have been so large that dialysis failed to reduce their concentration in the blood. Indeed, of the five patients that combined dialysis with a diet devoid of gluten and casein, all either improved significantly or became entirely normal (Cade et al., 2000).

In psychotic children (Gillberg et al., 1985), schizophrenia patients (Lindström et al., 1986), and women with postpartum psychosis (Lindström et al., 1984), larger-than-normal amounts of exorphins have been detected in the cerebrospinal fluid. Exorphins clearly do not belong there. In the presence of faulty barriers, though, they could migrate from the gut to the blood (prompting an immune reaction) and from there to the cerebrospinal fluid. In people with schizophrenia (unlike in healthy individuals) the more antibodies against gluten one finds in the blood, the more one finds in the cerebrospinal fluid (Severance et al., 2015). This correlation suggests a larger diffusion of antibodies from one place to the other in patients than in nonpatients, pointing to some barrier dysregulation-possibly subtle or transient. It is worth recalling that gluten comes prepackaged with the ability to cause such dysregulation itself.

\section{DIET AS A CURE}

Evidence that a diet devoid of wheat (and possibly of dairy as well, given the similarity between gluten and casein) can cure some patients with mental illness has been available for nearly 50 years. Yet because other patients-especially in newer and better studies-have not changed on the diet, such evidence has been variously downplayed, discredited, or dismissed. As a result, the message has made it neither to patients and their caretakers nor to psychologists and psychiatrists. After looking at all of these dietary intervention studies, we have come to believe that this lack of communication is a mistake.

Most studies have been run on schizophrenia patients kept in psychiatric wards, where meals could be tightly supervisioned. Patients on a grain-and-milk-free diet were either discharged or transferred from a locked to an open ward sooner than patients on a grain-rich diet (Dohan et al., 1969; Dohan and Grasberger, 1973). The effect was canceled when, blind to both patients and staff, the grain-and-milk-free diet was supplemented with gluten. A double-blind, placebo-controlled, longitudinal study with very similar results was impressive enough to get into the journal Science (Singh and Kay, 1976). Here schizophrenia patients kept on a grain-and-milk-free diet worsened on 30 out of 39 behavioral measures when a "special drink" they were given daily contained gluten and recovered when it contained soy flour instead. 
Abstention from gluten and casein, especially when protracted for several months, also benefits a proportion of children with autism spectrum disorders (for a review, see Whiteley et al., 2013). In one study that followed 70 such children who had not previously responded to any therapy, this proportion reached, after 3 months on the diet, an impressive 80\% (Cade et al., 2000).

In gluten-sensitive people, long-term wheat consumption could potentially lead to permanent damage (Kalaydjian et al., 2006; Hadjivassiliou et al., 2010); thus one does not necessarily anticipate change in chronic patients. Still, on gluten-free diets, clear improvements in psychiatric symptoms have been observed in severely disturbed schizophrenia patients who were unresponsive to any form of treatment and had spent much of their lives in institutions (Rice et al., 1978; Vlissides et al., 1986; see also Cade et al., 2000). Some of these patients worsened dramatically as soon as gluten was reintroduced.

Improvement in mental health on a gluten-free diet should, of course, only be expected for individuals that have an adverse physical reaction to wheat, expressed for example as glutenrelated antibodies. Indeed, in a small study on eight chronic schizophrenia patients who were shown not to react to gluten, none improved on a gluten-and-milk-free diet (Potkin et al., 1981). To date, only case studies have focused specifically on the subset of patients that is demonstrably sensitive to wheat. In each and every case, the results of a gluten-free diet have been impressive. Clear improvement has been observed in two patients with schizophrenia (Jackson et al., 2012b) and two with dementia (Lurie et al., 2008). Full recoveries have been separately reported for three patients with severe psychotic symptoms (De Santis et al., 1997; Eaton et al., 2015; Lionetti et al., 2015).

Ironically, the greater the potential benefit of a change in diet, the greater the resistance to it may be (Wadley and Martin, 1993). Grain's exorphins can create addiction. It has been estimated that half of the people that are hypersensitive crave the very food that causes them harm and experience withdrawal symptoms when they remove it from their diet (Brostoff and Gamlin, 1989). Remarkably, one untreatable, high-security-ward schizophrenia patient who had made a miraculous recovery on a gluten-free diet became violent and extremely disturbed when gluten was reintroduced. At that point, he was unable or unwilling to resume the gluten-free diet that would save him (Vlissides et al., 1986).

\section{CONCLUSION}

We have shown that in all of us bread makes the gut wall more permeable, encouraging the migration of toxins and undigested food particles to sites where they can alert the immune system. We have shown that in all of us the digestion of grain and dairy generates opioid-like compounds, and that these cause mental derangement if they make it to the brain.

Together, these pieces of evidence prompt the question of why not all of us develop psychotic symptoms on a diet of bread and milk. One plausible answer (Severance et al., 2015) is that the individuals who ultimately come down with these symptoms might be carrying an "immune defect" such that exorphins, once in the blood, either attract too much attention from the immune system or escape detection altogether. The resulting antibodies (in the former case) or the exorphins themselves (in the latter) could then gain access to the brain. They would arrive there from the bloodstream, either directly or via the cerebrospinal fluid, by way of faulty barriers. An alternative idea is that the genetic defect is not in the immune system, but in the enzymes involved in breaking down exorphins in either the gut or the blood (Dohan, 1980; see also Reichelt et al., 1996).

Even though wheat causes them serious harm, most individuals with celiac disease are unaware they have the illness, and for the rest of us no test is currently available that can conclusively reveal whether we are hypersensitive to wheat. The evidence is overpowering, though, that such hypersensitivity can bring with it mental disturbances like schizophrenia, bipolar disorder, depression, anxiety, and autism. Patients who have been demonstrated to be hypersensitive have either improved substantially or even been cured completely of their mental symptoms on a wheat-and-dairy-free diet. For all the others, wheat-sensitivity tests notwithstanding, we advocate trying the elimination of wheat and dairy or at least gluten and casein-for diagnostic purposes if nothing else. Unlike with pharmacological treatments, there have been no reports of harmful side effects. Actually, contrary to common wisdom, whole grains rank next to last in nutrient density among food groups (Cordain et al., 2005); they are nutrient-dense only in their raw, inedible state (Lalonde, 2012). Hence, replacing grains with vegetables, fruit and nuts, meats, and seafood actually increases the vitamin and mineral content of the diet.

Bread is the very symbol of food, and learning that it can threaten our mental wellbeing may come as a shock to many. Yet bread is not alone; like it, other foodstuffs, such as milk, rice, and corn, release exorphins during digestion. Wheat, rice, and corn are the staples of over 4 billion people. Another popular substance, sugar, is prominent in many of our supermarket products and hidden in a myriad others. While not a source of exorphins, sugar provokes the release of endorphins and can induce-with addiction-associated neurophysiological changes-impressive craving, bingeing, and withdrawal problems (Ahmed et al., 2013).

Psychologists and psychiatrists typically pay much attention to their patients' aberrant eating habits. They may wish to keep an eye on their normal eating habits as well.

\section{AUTHOR CONTRIBUTIONS}

PK wrote part of the first draft; PB wrote part of the first draft and the final version. Both authors conceived the work, searched and studied the literature, and contributed to the viewpoint that the article expresses.

\section{ACKNOWLEDGMENTS}

We thank Caterina Trainito for participating in the earlier stages of this work and Tiziano Gomiero for many discussions on agriculture-related topics. 


\section{REFERENCES}

Ahmed, S. H., Guillem, K., and Vandaele, Y. (2013). Sugar addiction: pushing the drug-sugar analogy to the limit. Curr. Opin. Clin. Nutr. Metab. Care 16, 434-439. doi: 10.1097/MCO.0b013e328361c8b8

Alcock, J., Maley, C. C., and Aktipis, C. A. (2014). Is eating behavior manipulated by the gastrointestinal microbiota? Evolutionary pressures and potential mechanisms. Bioessays 36, 940-949. doi: 10.1002/bies.2014 00071

Atchison, J., Head, L., and Gates, A. (2010). Wheat as food, wheat as industrial substance; comparative geographies of transformation and mobility. Geoforum 41, 236-246. doi: 10.1016/j.geoforum.2009.09.006

Barreau, F., Ferrier, L., Fioramonti, J., and Bueno, L. (2004). Neonatal maternal deprivation triggers long term alterations in colonic epithelial barrier and mucosal immunity in rats. Gut 53, 501-506. doi: 10.1136/gut.2003. 024174

Biesiekierski, J. R., Newnham, E. D., Irving, P. M., Barrett, J. S., Haines, M., Doecke, J. D., et al. (2011). Gluten causes gastrointestinal symptoms in subjects without celiac disease: a double-blind randomized placebo-controlled trial. Am. J. Gastroenterol. 106, 508-514. doi: 10.1038/ajg.2010.487

Biesiekierski, J. R., Peters, S. L., Newnham, E. D., Rosella, O., Muir, J. G., and Gibson, P. R. (2013). No effects of gluten in patients with self-reported nonceliac gluten sensitivity after dietary reduction of fermentable, poorly absorbed, short-chain carbohydrates. Gastroenterology 145, 320.e1-328.e1. doi: 10.1053/j. gastro.2013.04.051

Bischoff, S. C., Barbara, G., Buurman, W., Ockhuizen, T., Schulzke, J. D., Serino, M., et al. (2014). Intestinal permeability-a new target for disease prevention and therapy. BMC Gastroenterol. 14:189. doi: 10.1186/s12876-0140189-7

Boecker, H., Sprenger, T., Spilker, M. E., Henriksen, G., Koppenhoefer, M., Wagner, K. J., et al. (2008). The runner's high: opioidergic mechanisms in the human brain. Cereb. Cortex 18, 2523-2531. doi: 10.1093/cercor/bhn013

Boggiano, M. M., Chandler, P. C., Viana, J. B., Oswald, K. D., Maldonado, C. R., and Wauford, P. K. (2005). Combined dieting and stress evoke exaggerated responses to opioids in binge-eating rats. Behav. Neurosci. 119, 1207-1214. doi: 10.1037/0735-7044.119.5.1207

Broadwell, R. D., Balin, B. J., and Salcman, M. (1988). Transcytotic pathway for blood-borne protein through the blood-brain barrier. Proc. Natl. Acad. Sci. U S A 85, 632-636. doi: 10.1073/pnas.85.2.632

Brostoff, J., and Gamlin, L. (1989). The Complete Guide to Food Allergy and Intolerance. New York, NY: Crown.

Buscaino, G. A. (1978). "The amino-hepato-entero-toxic theory of schizophrenia: an historical evaluation," in The Biological Basis of Schizophrenia, eds G. Hemmings and W. A. Hemmings (Lancaster, UK: MTP Press), 45-54.

Buscaino, V. M. (1953). Patologia extraneurale della schizofrenia: fegato, tubo digerente, sistema reticolo-endoteliale. Acta. Neurol. 8, 1-60.

Cade, R., Privette, M., Fregly, M., Rowland, N., Sun, Z. J., Zele, V., et al. (2000). Autism and schizophrenia: intestinal disorders. Nutr. Neurosci. 3, 57-72. doi: 10.3109/10284150009163451

Carr, C. P., Martins, C. M., Stingel, A. M., Lemgruber, V. B., and Juruena, M. F. (2013). The role of early life stress in adult psychiatric disorders: a systematic review according to childhood trauma subtypes. J. Nerv. Ment. Dis. 201, 1007-1020. doi: 10.1097/NMD.0000000000000049

Cascella, N. G., Santora, D., Gregory, P., Kelly, D. L., Fasano, A., and Eaton, W. W. (2013). Increased prevalence of transglutaminase 6 antibodies in sera from schizophrenia patients. Schizophr. Bull. 39, 867-871. doi: 10. 1093/schbul/sbs064

Cass, H., Gringras, P., March, J., McKendrick, I., O’Hare, A. E., Owen, L., et al. (2008). Absence of urinary opioid peptides in children with autism. Arch. Dis. Child. 93, 745-750. doi: 10.1136/adc.2006.114389

Catassi, C., Kryszak, D., Bhatti, B., Sturgeon, C., Helzlsouer, K., Clipp, S. L., et al. (2010). Natural history of celiac disease autoimmunity in a U S A cohort followed since 1974. Ann. Med. 42, 530-538. doi: 10.3109/07853890.2010. 514285

Catassi, C., Rätsch, I. M., Fabiani, E., Ricci, S., Bordicchia, F., Pierdomenico, R., et al. (1995). High prevalence of undiagnosed coeliac disease in 5280 Italian students screened by antigliadin antibodies. Acta Paediatr. 84, 672-676. doi: 10 . 1111/j.1651-2227.1995.tb13725.x
Cohen, N. M. (1987). "The significance of long-term changes in human diet and food economy," in Food and Evolution: Toward a Theory of Human Food Habits, eds M. Harris and E. B. Ross (Philadelphia: Temple University Press), 261-284.

Cordain, L., Eaton, S. B., Sebastian, A., Mann, N., Lindeberg, S., Watkins, B. A., et al. (2005). Origins and evolution of the Western diet: health implications for the 21st century. Am. J. Clin. Nutr. 81, 341-354.

Daulatzai, M. A. (2015). Non-celiac gluten sensitivity triggers gut dysbiosis, neuroinflammation, gut-brain axis dysfunction and vulnerability for dementia. CNS Neurol. Disord. Drug Targets 14, 110-131. doi: 10. 2174/1871527314666150202152436

De Giorgio, R., Volta, U., and Gibson, P. R. (2016). Sensitivity to wheat, gluten and FODMAPs in IBS: facts or fiction? Gut 65, 169-178. doi: 10.1136/gutjnl-2015309757

De Santis, A., Addolorato, G., Romito, A., Caputo, S., Giordano, A., Gambassi, G., et al. (1997). Schizophrenic symptoms and SPECT abnormalities in a coeliac patient: regression after a gluten-free diet. J. Intern. Med. 242, 421-423. doi: 10. 1046/j.1365-2796.1997.00200.x

Dhabhar, F. S. (2009). Enhancing versus suppressive effects of stress on immune function: implications for immunoprotection and immunopathology. Neuroimmunomodulation 16, 300-317. doi: 10.1159/000216188

Dinan, T. G., Stilling, R. M., Stanton, C., and Cryan, J. F. (2015). Collective unconscious: how gut microbes shape human behavior. J. Psychiatr. Res. 63, 1-9. doi: 10.1016/j.jpsychires.2015.02.021

Diosdado, B., van Oort, E., and Wijmenga, C. (2005). "Coelionomics": towards understanding the molecular pathology of coeliac disease. Clin. Chem. Lab. Med. 43, 685-695. doi: 10.1515/cclm.2005.117

Dixon, J. M. S. (1960). The fate of bacteria in the small intestine. J. Pathol. Bacteriol. 79, 131-140. doi: 10.1002/path.1700790116

Dohan, F. C. (1966a). Wartime changes in hospital admissions for schizophrenia. A comparison of admission for schizophrenia and other psychoses in six countries during World War II. Acta Psychiatr. Scand. 42, 1-23. doi: 10.1111/j. 1600-0447.1966.tb01912.x

Dohan, F. C. (1966b). Wheat "consumption" and hospital admissions for schizophrenia during World War II. A preliminary report. Am. J. Clin. Nutr. $18,7-10$.

Dohan, F. C. (1980). Hypothesis: genes and neuroactive peptides from food as cause of schizophrenia. Adv. Biochem. Psychopharmacol. 22, 535-548.

Dohan, F. C., and Grasberger, J. C. (1973). Relapsed schizophrenics: earlier discharge from the hospital after cereal-free, milk-free diet. Am. J. Psychiatry 130, 685-688. doi: 10.1176/ajp.130.6.685

Dohan, F. C., Grasberger, J. C., Lowell, F. M., Johnston, H. T. Jr., and Arbegast, A. W. (1969). Relapsed schizophrenics: more rapid improvement on a milkand cereal-free diet. Br. J. Psychiatry 115, 595-596. doi: 10.1192/bjp.115. 522.595

Dohan, F. C., Harper, E. H., Clark, M. H., Rodrigue, R. B., and Zigas, V. (1984). Is schizophrenia rare if grain is rare? Biol. Psychiatry 19, 385-399.

Drysdale, A., Deacon, R., Lewis, P., Olley, J., Electricwala, A., and Sherwood, R. (1982). A peptide-containing fraction of plasma from schizophrenic patients which binds to opiate receptors and induces hyper-reactivity in rats. Neuroscience 7, 1567-1573. doi: 10.1016/0306-4522(82)90265-2

Eaton, W. W., Chen, L.-Y., Dohan, F. C. Jr., Kelly, D. L., and Cascella, N. (2015). Improvement in psychotic symptoms after a gluten-free diet in a boy with complex autoimmune illness. Am. J. Psychiatry 172, 219-221. doi: 10. 1176/appi.ajp.2014.14040550

El Asmar, R., Panigrahi, P., Bamford, P., Berti, I., Not, T., Coppa, G. V., et al. (2002). Host-dependent zonulin secretion causes the impairment of the small intestine barrier function after bacterial exposure. Gastroenterology 123, 1607-1615. doi: 10.1053/gast.2002.36578

Emrich, H. M., Cording, C., Pirée, S., Kölling, A., von Zerssen, D., and Herz, A. (1977). Indication of an antipsychotic action of the opiate antagonist naloxone. Pharmakopsychiatr. Neuropsychopharmakol. 10, 265-270. doi: 10.1055/s-00281094547

Fasano, A. (2009). Surprises from celiac disease. Sci. Am. 301, 54-61. doi: 10. 1038/scientificamerican0809-54

Fasano, A. (2011). Zonulin and its regulation of intestinal barrier function: the biological door to inflammation, autoimmunity and cancer. Physiol. Rev. 91, 151-175. doi: 10.1152/physrev.00003.2008 
Fasano, A. (2012). Leaky gut and autoimmune diseases. Clin. Rev. Allergy Immunol. 42, 71-78. doi: 10.1007/s12016-011-8291-x

Fasano, A., Sapone, A., Zevallos, V., and Schuppan, D. (2015). Nonceliac gluten and wheat sensitivity. Gastroenterology 148, 1195-1204. doi: 10.1053/j.gastro. 2014.12.049

Fasano, A., Uzzau, S., Fiore, C., and Margaretten, K. (1997). The enterotoxic effect of zonula occludens toxin on rabbit small intestine involves the paracellular pathway. Gastroenterology 112, 839-846. doi: 10.1053/gast.1997. v112.pm9041245

Finizio, M., Quaremba, G., Mazzacca, G., and Ciacci, C. (2005). Large forehead: a novel sign of undiagnosed coeliac disease. Dig. Liver. Dis. 37, 659-664. doi: 10. 1016/j.dld.2005.04.014

Flodrová, D., Benkovská, D., and Laštovičková, M. (2015). Study of quantitative changes of cereal allergenic proteins after food processing. J. Sci. Food Agric. 95, 983-990. doi: 10.1002/jsfa.6773

Fuss, J., Steinle, J., Bindila, L., Auer, M. K., Kirchherr, H., Lutz, B., et al. (2015). A runner's high depends on cannabinoid receptors in mice. Proc. Natl. Acad. Sci. U S A 112, 13105-13108. doi: 10.1073/pnas.1514996112

Galipeau, H. J., McCarville, J. L., Huebener, S., Litwin, O., Meisel, M., Jabri, B., et al. (2015). Intestinal microbiota modulates gluten-induced immunopathology in humanized mice. Am. J. Pathol. 185, 2969-2982. doi: 10.1016/j.ajpath.2015. 07.018

Gasbarrini, G., Ciccocioppo, R., De Vitis, I., Corazza, G. R., and Club del Tenue Study Group. (2001). Coeliac disease in the elderly. A multicentre Italian study. Gerontology 47, 306-310. doi: 10.1159/000052819

Genuis, S. J., and Lobo, R. A. (2014). Gluten sensitivity presenting as a neuropsychiatric disorder. Gastroenterol. Res. Pract. 2014:293206. doi: 10. $1155 / 2014 / 293206$

Gillberg, C., Terenius, L., and Lönnerholm, G. (1985). Endorphin activity in childhood psychosis. Spinal fluid levels in 24 cases. Arch. Gen. Psychiatry 42, 780-783. doi: 10.1001/archpsyc.1985.01790310042005

Glass, M. J., Grace, M., Cleary, J. P., Billington, C. J., and Levine, A. S. (1996). Potency of naloxone's anorectic effect in rats is dependent on diet preference. Am. J. Physiol. 271, R217-R221.

Greco, L., Romino, R., Coto, I., Di Cosmo, N., Percopo, S., Maglio, M., et al. (2002). The first large population based twin study of coeliac disease. Gut 50, 624-628. doi: $10.1136 /$ gut.50.5.624

Guisinger, S. (2003). Adapted to flee famine: adding an evolutionary perspective on anorexia nervosa. Psychol. Rev. 110, 745-761. doi: 10.1037/0033-295x.110. 4.745

Hadjivassiliou, M., Sanders, D. S., Grünewald, R. A., Woodroofe, N., Boscolo, S., and Aeschlimann, D. (2010). Gluten sensitivity: from gut to brain. Lancet Neurol. 9, 318-330. doi: 10.1016/S1474-4422(09)70290-X

Hagen, E. H., Sullivan, R. J., Schmidt, R., Morris, G., Kempter, R., and Hammerstein, P. (2009). Ecology and neurobiology of toxin avoidance and the paradox of drug reward. Neuroscience 160, 69-84. doi: 10.1016/j.neuroscience. 2009.01.077

Hashimoto, S., and Hagino, A. (1989). Wheat germ agglutinin, concanavalin A and lens culinalis agglutinin block the inhibitory effect of nerve growth factor on cell-free phosphorylation of Nsp100 in PC12h cells. Cell Struct. Funct. 14, 87-93. doi: 10.1247/csf.14.87

Helander, H. F., and Fändriks, L. (2014). Surface area of the digestive tract revisited. Scand. J. Gastroenterol. 49, 681-689. doi: 10.3109/00365521.2014. 898326

Hemmings, W. A. (1978). The entry into the brain of large molecules derived from dietary protein. Proc. R. Soc. Lond. B. Biol. Sci. 200, 175-192. doi: 10.1098/rspb. 1978.0014

Herrera-Marschitz, M., Terenius, L., Grehn, L., and Ungerstedt, U. (1989). Rotational behaviour produced by intranigral injections of bovine and human beta-casomorphins in rats. Psychopharmacology (Berl) 99, 357-361. doi: 10. 1007/bf00445557

Hole, K., Bergslien, H., Jørgensen, H. A., Berge, O. G., Reichelt, K. L., and Trygstad, O. E. (1979). A peptide-containing fraction in the urine of schizophrenic patients which stimulates opiate receptors and inhibits dopamine uptake. Neuroscience 4, 1883-1893. doi: 10.1016/0306-4522(79) 90062-9

Hollon, J., Puppa, E. L., Greenwald, B., Goldberg, E., Guerrerio, A., and Fasano, A. (2015). Effect of gliadin on permeability of intestinal biopsy explants from celiac disease patients and patients with non-celiac gluten sensitivity. Nutrients 7, 1565-1576. doi: 10.3390/nu7031565

Inomata, N. (2009). Wheat allergy. Curr. Opin. Allergy Clin. Immunol. 9, 238-243. doi: 10.1097/ACI.0b013e32832aa5bc

Jackson, J. R., Eaton, W. W., Cascella, N. G., Fasano, A., and Kelly, D. L. (2012a). Neurologic and psychiatric manifestations of celiac disease and gluten sensitivity. Psychiatr. Q. 83, 91-102. doi: 10.1007/s11126-011-9186-y

Jackson, J., Eaton, W., Cascella, N., Fasano, A., Warfel, D., Feldman, S., et al. (2012b). A gluten-free diet in people with schizophrenia and anti-tissue transglutaminase or anti-gliadin antibodies. Schizophr. Res. 140, 262-263. doi: 10.1016/j.schres.2012.06.011

Janzen, D. H. (1984). Dispersal of small seeds by big herbivores: foliage is the fruit. Am. Nat. 123, 338-353. doi: 10.1086/284208

Jensen-Jarolim, E., Gajdzik, L., Haberl, I., Kraft, D., Scheiner, O., and Graf, J. (1998). Hot spices influence permeability of human intestinal epithelial monolayers. J. Nutr. 128, 577-581.

Jørgensen, H. A., and Cappelen, C. (1982). Naloxone-induced reduction of schizophrenic symptoms. Acta Psychiatr. Scand. 65, 370-374. doi: 10.1111/j. 1600-0447.1982.tb00858.x

Kagnoff, M. F., Paterson, Y. J., Kumar, P. J., Kasarda, D. D., Carbone, F. R., Unsworth, D. J., et al. (1987). Evidence for the role of a human intestinal adenovirus in the pathogenesis of coeliac disease. Gut 28, 995-1001. doi: 10. 1136/gut.28.8.995

Kalaydjian, A. E., Eaton, W., Cascella, N., and Fasano, A. (2006). The gluten connection: the association between schizophrenia and celiac disease. Acta Psychiatr. Scand. 113, 82-90. doi: 10.1111/j.1600-0447.2005.00687.x

Karyekar, C. S., Fasano, A., Raje, S., Lu, R., Dowling, T. C., and Eddington, N. D. (2003). Zonula occludens toxin increases the permeability of molecular weight markers and chemotherapeutic agents across the bovine brain microvessel endothelial cells. J. Pharm. Sci. 92, 414-423. doi: 10.1002/jps.10310

Kasarda, D. D. (1997). "Gluten and gliadin: precipitating factors in coeliac disease," in Coeliac Disease. Proceedings of the Seventh International Symposium on Coeliac Disease., eds M. Mäki, P. Collin, and J. K. Visakorpi (Tampere, Finland: Coeliac Disease Study Group), 195-212.

Kendler, K. S., Karkowski, L. M., and Prescott, C. A. (1999). Causal relationship between stressful life events and the onset of major depression. Am. J. Psychiatry 156, 837-841. doi: 10.1176/ajp.156.6.837

Kennedy, D. O., and Wightman, E. L. (2011). Herbal extracts and phytochemicals: plant secondary metabolites and the enhancement of human brain function. Adv. Nutr. 2, 32-50. doi: 10.3945/an.110.000117

Kostyra, E., Sienkiewicz-Szlapka, E., Jarmolowska, B., Krawczuk, S., and Kostyra, H. (2004). Opioid peptides derived from milk proteins. Pol. J. Food Nutr. Sci. $13,25-35$.

Kramer, P., and Bressan, P. (2015). Humans as superorganisms: how microbes, viruses, imprinted genes and other selfish entities shape our behavior. Perspect. Psychol. Sci. 10, 464-481. doi: 10.1177/1745691615583131

Kranich, J., Maslowski, K. M., and Mackay, C. R. (2011). Commensal flora and the regulation of inflammatory and autoimmune responses. Semin. Immunol. 23 , 139-145. doi: 10.1016/j.smim.2011.01.011

Kucek, L. K., Veenstra, L. D., Amnuaycheewa, P., and Sorrells, M. E. (2015). A grounded guide to gluten: how modern genotypes and processing impact wheat sensitivity. Compr. Rev. Food. Sci. F. 14, 285-302. doi: 10.1111/1541-4337.12129

Lalonde, M. P. (2012). Nutrient density: sticking to the essentials. [Paper presented at the Ancestral Health Symposium 2012]. Cambridge, MA. Available online at: https://www.youtube.com/watch?v=HwbY12qZcF4. Accessed October 5, 2015.

Larsen, C. S. (1995). Biological changes in human populations with agriculture. Annu. Rev. Anthropol. 24, 185-213. doi: 10.1146/annurev.anthro.24.1.185

Lindström, L. H., Besev, G., Gunne, L. M., and Terenius, L. (1986). CSF levels of receptor-active endorphins in schizophrenic patients: correlations with symptomatology and monoamine metabolites. Psychiatry Res. 19, 93-100. doi: 10.1016/0165-1781(86)90001-6

Lindström, L. H., Nyberg, F., Terenius, L., Bauer, K., Besev, G., Gunne, L. M., et al. (1984). CSF and plasma beta-casomorphin-like opioid peptides in postpartum psychosis. Am. J. Psychiatry 141, 1059-1066. doi: 10.1176/ajp.141. 9.1059

Lionetti, E., Leonardi, S., Franzonello, C., Mancardi, M., Ruggieri, M., and Catassi, C. (2015). Gluten psychosis: confirmation of a new clinical entity. Nutrients 7, 5532-5539. doi: 10.3390/nu7075235 
Lister, J., Fletcher, P. J., Nobrega, J. N., and Remington, G. (2015). Behavioral effects of food-derived opioid-like peptides in rodents: implications for schizophrenia? Pharmacol. Biochem. Behav. 134, 70-78. doi: 10.1016/j.pbb. 2015.01.020

Lohi, S., Mustalahti, K., Kaukinen, K., Laurila, K., Collin, P., Rissanen, H., et al. (2007). Increasing prevalence of coeliac disease over time. Aliment. Pharmacol. Ther. 26, 1217-1225. doi: 10.1111/j.1365-2036.2007.03502.x

Louis, P. (2012). Does the human gut microbiota contribute to the etiology of autism spectrum disorders? Dig. Dis. Sci. 57, 1987-1989. doi: 10.1007/s10620012-2286-1

Ludvigsson, J. F., Osby, U., Ekbom, A., and Montgomery, S. M. (2007a). Coeliac disease and risk of schizophrenia and other psychosis: a general population cohort study. Scand. J. Gastroenterol. 42, 179-185. doi: 10. 1080/00365520600863472

Ludvigsson, J. F., Reutfors, J., Osby, U., Ekbom, A., and Montgomery, S. M. (2007b). Coeliac disease and risk of mood disorders-a general populationbased cohort study. J. Affect. Disord. 99, 117-126. doi: 10.1016/j.jad.2006. 08.032

Ludvigsson, J. F., Reichenberg, A., Hultman, C. M., and Murray, J. A. (2013). A nationwide study of the association between celiac disease and the risk of autistic spectrum disorders. JAMA Psychiatry 70, 1224-1230. doi: 10. 1001/jamapsychiatry.2013.2048

Lurie, Y., Landau, D.-A., Pfeffer, J., and Oren, R. (2008). Celiac disease diagnosed in the elderly. J. Clin. Gastroenterol. 42, 59-61. doi: 10.1097/01.mcg. 0000247995.12087.7b

Malnick, S. D., Atali, M., Lurie, Y., Fraser, G., and Geltner, D. (1998). Celiac sprue presenting during the puerperium: a report of three cases and a review of the literature. J. Clin. Gastroenterol. 26, 164-166. doi: 10.1097/00004836199804000-00002

Mamone, G., Nitride, C., Picariello, G., Addeo, F., Ferranti, P., and Mackie, A. (2015). Tracking the fate of pasta (T. durum semolina) immunogenic proteins by in vitro simulated digestion. J. Agric. Food. Chem. 63, 2660-2667. doi: 10. 1021/jf505461x

Margules, D. L. (1979). $\beta$-endorphin and endoloxone: hormones of the autonomic nervous system for the conservation or expenditure of bodily resources and energy in anticipation of famine or feast. Acta Diabetol. 3, 155-162.

Margules, D. L. (1988). "Energy balance and opioid receptors: epsilons in the periphery promote conservation; $\kappa$ and $\delta$ in the CNS permit expenditures," in The Eating Disorders: Medical and Psychological Bases of Diagnosis and Treatment, eds B. J. Blinder, B. F. Chaitin and R. S. Goldstein (New York, NY: PMA Publishing), 21-27.

Marrazzi, M. A., Bacon, J. P., Kinzie, J., and Luby, E. D. (1995). Naltrexone use in the treatment of anorexia nervosa and bulimia nervosa. Int. Clin. Psychopharmacol. 10, 163-172. doi: 10.1097/00004850-199510030-00005

Meddings, J. B., Jarand, J., Urbanski, S. J., Hardin, J., and Gall, D. G. (1999). Increased gastrointestinal permeability is an early lesion in the spontaneously diabetic BB rat. Am. J. Physiol. 276, G951-G957.

Meisel, H., and FitzGerald, R. J. (2000). Opioid peptides encrypted in intact milk protein sequences. Br. J. Nutr. 84, S27-S31. doi: 10.1017/S000711450 $000221 \mathrm{X}$

Miner-Williams, W. M., Stevens, B. R., and Moughan, P. J. (2014). Are intact peptides absorbed from the healthy gut in the adult human? Nutr. Res. Rev. 27, 308-329. doi: 10.1017/s0954422414000225

Murphy, D. J. (2007). People Plants and Genes: The Story of Crops and Humanity. New York, NY: Oxford University Press.

Olivares, M., Neef, A., Castillejo, G., Palma, G. D., Varea, V., Capilla, A., et al. (2015). The HLA-DQ2 genotype selects for early intestinal microbiota composition in infants at high risk of developing coeliac disease. Gut 64, 406-417. doi: 10.1136/gutjnl-2014-306931

Potkin, S. G., Weinberger, D., Kleinman, J., Nasrallah, H., Luchins, D., Bigelow, L., et al. (1981). Wheat gluten challenge in schizophrenic patients. Am. J. Psychiatry 138, 1208-1211. doi: 10.1176/ajp.138.9.1208

Purohit, V., Bode, J. C., Bode, C., Brenner, D. A., Choudhry, M. A., Hamilton, F., et al. (2008). Alcohol, intestinal bacterial growth, intestinal permeability to endotoxin and medical consequences: summary of a symposium. Alcohol. 42, 349-361. doi: 10.1016/j.alcohol.2008.03.131

Pusztai, A., Ewen, S. W., Grant, G., Brown, D. S., Stewart, J. C., Peumans, W. J., et al. (1993). Antinutritive effects of wheat-germ agglutinin and other
N-acetylglucosamine-specific lectins. Br. J. Nutr. 70, 313-321. doi: 10 . 1079/bjn19930124

Reichelt, K. L., Seim, A. R., and Reichelt, W. H. (1996). Could schizophrenia be reasonably explained by Dohan's hypothesis on genetic interaction with a dietary peptide overload? Prog. Neuropsychopharmacol. Biol. Psychiatry 20, 1083-1114. doi: 10.1016/s0278-5846(96)00099-1

Rice, J. R., Ham, C. H., and Gore, W. E. (1978). Another look at gluten in schizophrenia. Am. J. Psychiatry 135, 1417-1418. doi: 10.1176/ajp.135. 11.1417

Roy, A., Roy, M., Deb, S., Unwin, G., and Roy, A. (2015). Are opioid antagonists effective in attenuating the core symptoms of autism spectrum conditions in children: a systematic review. J. Intellect. Disabil. Res. 59, 293-306. doi: 10. $1111 /$ jir. 12122

Rubio-Tapia, A., Kyle, R. A., Kaplan, E. L., Johnson, D. R., Page, W., Erdtmann, F., et al. (2009). Increased prevalence and mortality in undiagnosed celiac disease. Gastroenterology 137, 88-93. doi: 10.1053/j.gastro.2009.03.059

Sahley, T. L., and Panksepp, J. (1987). Brain opioids and autism: an updated analysis of possible linkages. J. Autism. Dev. Disord. 17, 201-216. doi: 10. 1007/bf01495056

Sapone, A., Bai, J. C., Ciacci, C., Dolinsek, J., Green, P. H., Hadjivassiliou, M., et al. (2012). Spectrum of gluten-related disorders: consensus on new nomenclature and classification. BMC Med. 10:13. doi: 10.1186/1741-7015-10-13

Sawasdivorn, S., Wanthanaphuti, P., Pue-arun, S., and Juansang, S. (2008). Situation of baby bottle use: is it suitable to recommend weaning by the age of one year? J. Med. Assoc. Thai. 91, S128-S135.

Sellitto, M., Bai, G., Serena, G., Fricke, W. F., Sturgeon, C., Gajer, P., et al. (2012). Proof of concept of microbiome-metabolome analysis and delayed gluten exposure on celiac disease autoimmunity in genetically at-risk infants. PLoS One 7:e33387. doi: 10.1371/journal.pone.0033387

Severance, E. G., Gressitt, K. L., Yang, S., Stallings, C. R., Origoni, A. E., Vaughan, C., et al. (2014). Seroreactive marker for inflammatory bowel disease and associations with antibodies to dietary proteins in bipolar disorder. Bipolar Disord. 16, 230-240. doi: 10.1111/bdi.12159

Severance, E. G., Prandovszky, E., Castiglione, J., and Yolken, R. H. (2015). Gastroenterology issues in schizophrenia: why the gut matters. Curr. Psychiatry Rep. 17:27. doi: 10.1007/s11920-015-0574-0

Singh, M. M., and Kay, S. R. (1976). Wheat gluten as a pathogenic factor in schizophrenia. Science 191, 401-402. doi: 10.1126/science. 1246624

Smale, S., and Bjarnason, I. (2003). Determining small bowel integrity following drug treatment. Br. J. Clin. Pharmacol. 56, 284-291. doi: 10.1046/j.1365-2125. 2003.01942.x

Söderholm, J. D., and Perdue, M. H. (2001). II. Stress and intestinal barrier function. Am. J. Physiol. Gastrointest. Liver Physiol. 280, G7-G13.

Sokolov, O., Kost, N., Andreeva, O., Korneeva, E., Meshavkin, V., Tarakanova, Y., et al. (2014). Autistic children display elevated urine levels of bovine casomorphin-7 immunoreactivity. Peptides 56, 68-71. doi: 10.1016/j.peptides. 2014.03.007

Sun, Z., and Cade, J. R. (1999). A peptide found in schizophrenia and autism causes behavioral changes in rats. Autism 3, 85-95. doi: 10 . $1177 / 1362361399003001007$

Sun, Z., Cade, J. R., Fregly, M. J., and Privette, R. M. (1999). $\beta$ Casomorphin induces Fos-like immunoreactivity in discrete brain regions relevant to schizophrenia and autism. Autism 3, 67-83. doi: 10 . $1177 / 1362361399003001006$

Teschemacher, H. (2003). Opioid receptor ligands derived from food proteins. Curr. Pharm. Des. 9, 1331-1344. doi: 10.2174/1381612033454856

Ulluwishewa, D., Anderson, R. C., McNabb, W. C., Moughan, P. J., Wells, J. M., and Roy, N. C. (2011). Regulation of tight junction permeability by intestinal bacteria and dietary components. J. Nutr. 141, 769-776. doi: 10.3945/jn.110. 135657

van den Broeck, H. C., de Jong, H. C., Salentijn, E. M., Dekking, L., Bosch, D., Hamer, R. J., et al. (2010). Presence of celiac disease epitopes in modern and old hexaploid wheat varieties: wheat breeding may have contributed to increased prevalence of celiac disease. Theor. Appl. Genet. 121, 1527-1539. doi: 10.1007/s00122-010-1408-4

Vanuytsel, T., van Wanrooy, S., Vanheel, H., Vanormelingen, C., Verschueren, S., Houben, E., et al. (2014). Psychological stress and corticotropin- 
releasing hormone increase intestinal permeability in humans by a mast cell-dependent mechanism. Gut 63, 1293-1299. doi: 10.1136/gutjnl-2013-3 05690

Vlissides, D. N., Venulet, A., and Jenner, F. A. (1986). A double-blind glutenfree/gluten-load controlled trial in a secure ward population. Br. J. Psychiatry 148, 447-452. doi: 10.1192/bjp.148.4.447

Vojdani, A., Kharrazian, D., and Mukherjee, P. S. (2014). The prevalence of antibodies against wheat and milk proteins in blood donors and their contribution to neuroimmune reactivities. Nutrients 6, 15-36. doi: 10 . 3390/nu6010015

Wadley, G., and Martin, A. (1993). The origins of agriculture: a biological perspective and a new hypothesis. Aust. Biol. 6, 96-105. Available online at: http://ranprieur.com/readings/origins.html.

Walusiak, J., Hanke, W., Górski, P., and Pałczyński, C. (2004). Respiratory allergy in apprentice bakers: do occupational allergies follow the allergic march? Allergy 59, 442-450. doi: 10.1111/j.1398-9995.2003. 00418.x

Whiteley, P., Shattock, P., Knivsberg, A. M., Seim, A., Reichelt, K. L., Todd, L., et al. (2013). Gluten- and casein-free dietary intervention for autism spectrum conditions. Front. Hum. Neurosci. 6:344. doi: 10.3389/fnhum.2012. 00344

Yeomans, M. R., and Gray, R. W. (1997). Effects of naltrexone on food intake and changes in subjective appetite during eating: evidence for opioid involvement in the appetizer effect. Physiol. Behav. 62, 15-21. doi: 10. 1016/s0031-9384(97)00101-7
Yeomans, M. R., and Gray, R. W. (2002). Opioid peptides and the control of human ingestive behaviour. Neurosci. Biobehav. Rev. 26, 713-728. doi: 10. 1016/s0149-7634(02)00041-6

Zanchi, C., Ventura, G., Di Leo, G., Orzes, N., Ronfani, L., Not, T., et al. (2013). Leonardo da Vinci meets celiac disease. J. Pediatr. Gastroenterol. Nutr. 56, 206-210. doi: 10.1097/MPG.0b013e31827114a4

Zioudrou, C., Streaty, R. A., and Klee, W. A. (1979). Opioid peptides derived from food proteins. The exorphins. J. Biol. Chem. 254, 2446-2449.

Conflict of Interest Statement: The authors declare that the research was conducted in the absence of any commercial or financial relationships that could be construed as a potential conflict of interest.

Despite currently receiving royalties from a publication based on the use of dietary intervention for autism and related conditions and being a shareholder of an online company that provides dietary information about the use of a gluten and casein free diet, the Reviewer PW and handling Editor declare that the process nevertheless met the standards of a fair and objective review.

Copyright (C) 2016 Bressan and Kramer. This is an open-access article distributed under the terms of the Creative Commons Attribution License (CC BY). The use, distribution and reproduction in other forums is permitted, provided the original author(s) or licensor are credited and that the original publication in this journal is cited, in accordance with accepted academic practice. No use, distribution or reproduction is permitted which does not comply with these terms. 